\title{
Research on Influence Factors of the Availability of Peasant Households' Agricultural Production Elements in China
}

\author{
Rui-qin LI ${ }^{1, a,{ }^{*}}$ \\ ${ }^{1}$ Post-doctor of Law Post-doctoral Station, Lecturer of Economics College, \\ Southwest University of Political Science \& Law, Chongqing, China. \\ aliruiqin2010@163.com
}

Keywords: Peasant households, Agricultural production elements, Availability.

\begin{abstract}
Peasant households who dominated agricultural production elements must pay price and experience processes. The domination naturally has the problem of "if or not", "how much" and "how difficultly" and so on. This paper answered the questions of what are key reasons of peasant household' agricultural production elements possession, and through what ways and mechanisms. Our researches indicated that the availability of peasant households' agricultural production elements comprehensively decided by the community resources endowment and geography conditions, elements supply and trade systems, elements markets and the ability of farmers.
\end{abstract}

\section{Introduction}

A great deal of researches about farmers economics always stated peasant households disposable agricultural production elements is fixed as the basic premise [1], to explore the optimal allocation of limited agricultural production elements and profit maximization of agricultural production [2, 3], but the disposable agricultural production elements' types, quality, quantity, use time limit, retrieval channels and access ways are rarely involved [4, 5]. In fact, peasant households dominated agricultural production elements must pay price and experience process. The species of elements agricultural production needed must match each other. Neither any element can exist effectively without the others because of their different functions on productions, although there are some alternative relationships between these elements. All kinds of agricultural production elements face the availability problem, and will eventually play an important role in elements allocation and agricultural incomes. With the rapid advances of industrialization and urbanization, a large number of rural labor forces transferring to non-agricultural industries, many rural populations transferring to towns, make rural populations and labors reduced year by year. In this situation the supply and demand of agricultural production elements have changed significantly, the disposable of elements has a certain variable conditions, and the opportunity of the availability of agricultural production elements improvement arrived. It has important theoretical and practical significances to explore the factors of the availability of production elements and find the key restricted obstacles [6]. Agricultural production elements can only be acquired in condition of elements existing, institutions allowing and markets trading effectively at same time. This article will analyze the influence ways and mechanisms of the major determinants for the availability of farmers' agricultural production elements. 


\section{The Function of Resources Endowment and Geography Conditions on the Availability of Peasant Households' Agricultural Production Elements}

Resources endowment reflects specific resources abundance within the scope of certain region, which has a direct impact on the supply situation of agricultural production elements farmers needed. Geographic conditions not only decide the supply status of agricultural production elements with the resources endowment, but also are the direct reflections of resources endowments status. The landform and geography location are the most critical geography conditions factors for the effectively obtaining of farmers' agricultural production elements. According to the research of the availability of agricultural production elements, this section will analyze the influence of the resources endowment, topography, geography location on farmers' agricultural production elements, especially on the lands, labors, capitals and technologies.

\section{The Function of the Resources Endowment}

The endowments of agricultural production elements farmers needed mainly embodied the type good or bad, the quality high or low, and the quantity more or less within the scope of famers reached. It is exactly the main emphasized content of the availability of farmers' agricultural production elements. Obviously, the obtaining of farmers' agricultural production elements must be firstly decided by the restriction of agricultural production elements endowments within certain scope they reached.

\section{The Function of the Topography}

Topography reflects the ups and downs status of the terrain within the scope of a certain region, which form the basic geography conditions for farmers' agricultural production and operation. In certain range, the landform characteristics can be simply divided into mountains, hills and plains. Except the labor element, the obtaining of the lands, capitals and technologies of farmers are influenced by the topography in a range of region. And the difficulties performance on the agricultural production elements obtaining and using difficulty, especially for the land. Under the condition of certain resources endowment, the stand or fall of landform becomes the important determinants of agricultural production elements' supply level.

\section{The Function of the Geography Location}

The concept of geography location put forward by the research of geography based on the theory of the location. It increases the link of the geography condition and phenomenon, and gives the geography factors to the geography concept. It is made from spatial or geography location theory aspects of nature, economics and social phenomena of concrete researches, one of the main research content and the study of economics phenomena. It makes the theory of location theory to research the phenomenon of nature, economics and society from the space or area, but one of the main research content is the study of economics phenomena. With rural markets economics gradually established and transformed, the obtaining of farmers' agricultural production elements will possibly break the confine of areas. There will be more and more farmers obtaining the required elements outside the area, and more and more production elements flowing outside the region. Thus the nature, economics and society characteristics of certain region determined by geography location have an important influence on the availability of farmers' agricultural production elements. 


\section{The Function of Institutions on the Availability of Peasant Households' Agricultural Production Elements}

The development and utilization of and the possession and trading of resources and elements will be subject to the institution constraints because of the pressure and requirements of the sustainable development. The development and utilization of and the possession and trading of other necessary elements agricultural production needed also will be subject to institution constraints. In other words, under the established condition of resources endowment and geography conditions, the supply and demand of agricultural production elements famers obtained are bound to be affected comprehensively by a variety of institutions. According to the main purpose of this study, this section will select the most direct affections of the formal and informal institutions for farmers' agricultural production elements obtaining such as property right institutions and trading institutions as the main analysis content.

\section{The Function of Rural Lands Institutions}

Farmers' land access must to be allowed within the scope of the access in the system, and the land access is invalid which didn't conform to the stipulations of the system. Rural land system has an important function on the availability of peasant households' land elements. And in these formal and informal systems, the formal system of land property rights system and land circulation system and the informal institutions of community custom and personal relationship network have significantly impact on the availability of farmers' land.

\section{The Function of Rural Labors Employment Institutions}

Farmers' labor forces are mainly coming from their families, but there is no lack of labor employment after production operation scale expanding. Because of the particularity of agricultural production and the irreversibility flow of labors from rural to urban. Peasant households' labor employment can only turn to the rural. The formal labor employment systems are almost not involved in rural, but many informal institutions are formed by a certain labor hiring traditions, customs and some unwritten rules because of the temporary or long term generally employment of rural labor forces. The informal institutions will no doubt have a certain impact on the employment of farmers' labors. The basic systems condition of farmers' labor forces employment in rural, formed by informal institutions such as the existing labor employment traditions, habitude and unwritten rules in rural, have major impacts on labor forces employment difficulty and costs, which will affect the availability of peasant households' labor element. Along with the gradually explored and established of formal rural labor force systems and the step by step regularization of informal rural labor forces systems, rural labor employment markets will be gradually formed and normalized, and the acquisition and availability of peasant households' labors will also change accordingly. For the rural labors less likely to return rural and engage in agricultural production and operation, and the non-agricultural employments have the strongest appeal to young labor force. The supply of excellent labor forces will be relatively nervous, and the availability of farmers' agricultural labor forces will decrease accordingly.

\section{The Function of Rural Finances Institutions}

Rural financial systems which serving various investments and financing activities in rural economics, is mainly used to guide and standardize the whole process of the financial activities such as the construction of rural financial institutions' organization 
structures, the supplying of the financial products and the operation of financial markets. Accept from their families' accumulation the funds element farmers required mainly loan from formal and informal finance institutions. The availability of capitals element must inevitably under the influence of rural finance systems. The most direct systems, which influent the obtain of farmers' capital elements, are the formal systems such as the loans supply systems of peasant households, the credit technology systems of farmers, the financial support systems in rural and the informal institutions such as community customs and private networks.

\section{The Function of Rural Technologies Institutions}

The main roles of agriculture technology systems are to standardize and promote the development and popularization of agriculture technologies. Agricultural technology systems will directly affect the may supply and effective supply of varieties, water and fertilizer, planting, breeding, prevention and cure of diseases and pests, facilities, machinery and other technic, and the actual use and obtain of farmers technologies. Agriculture technology systems will provide supports for agricultural production technologies, incent, induct and "promote agricultural science and technology cause economics", to affect the availability of farmers' technic elements jointly.

\section{The Function of Elements Markets on the Availability of Peasant Households' Agricultural Production Elements}

Because of the special systems in China, the initial endowment of lands, labors, capitals and technologies different farmers owned or controlled are relatively similar and less in specific scopes. If we want to ensure the progress of farmers' agricultural production smoothly and the optimal configuration of agricultural production elements, we must make all kinds of agricultural production elements can flow freely between different farmers. With the gradual reform of the rural markets, farmers' agricultural production and operation activities are no longer the closed self-sufficiency production and operation, and their connections with markets become more and more closely and inseparable. According to the main purpose of this study, this section will screen markets scale, degree of elements markets transparency and elements markets order which influence farmers' availability of agricultural production elements directly as main analysis contents.

\section{The Function of the Markets Size}

Markets size which reflects the size of markets relationship coverage and the volume of markets trading, is the concentrated reflection of subject number involving in elements transaction, the supply of elements, the transaction efficiency of elements and the development level of elements markets. The acquiring and the availability of farmers' agricultural production elements is closely related to the size of rural elements markets.

\section{The Function of the Markets Transparency}

Market transparency reflecting the information transmission status of markets, is the concentrated reflection of the completely degree of markets information, such as the amount of markets information, the true extent of information, the transmission channel of information, the transmission speed of information. The effectively obtaining of agricultural production elements farmers required will influent by the completely degree of markets information in rural elements markets. 


\section{The Function of the Markets Orders}

Markets order reflects the characteristics of the market operation rules' restriction on the markets operation order. Good markets orders are the main guarantee for the supply and demand body as the stability of the stability prediction and trading. Whether farmers can effectively obtain the required agricultural production elements or not is restricted by the order of rural elements markets.

\section{The Function of Abilities on the Availability of Peasant Households' Agricultural Production Elements}

Farmers' ability is a comprehensive concept, which can't use a single index to measure accurately. Surrounding the acquisition, farmers' ability can be measured by the opportunity grasping ability of farmers' agricultural production elements acquisition, the investment ability and social capitals these three aspects. The reason is that, whether formal or informal markets all filled with many trading information and opportunities of agricultural production elements. If farmers want to obtain agricultural production elements they must firstly focus on the supply and demand information of the elements and grasp the chance, at the same time farmers also need sufficient investment ability to change the obtaining opportunities of the agricultural production elements into reality. Except influent by the opportunity grasping ability and the investment ability, how many agricultural production elements farmers obtained and how the quality of the agricultural production elements farmers acquired, also will more or less influenced by peasant households' social capitals.

\section{The Function of the Opportunity Grasping Ability}

Resources endowment and geography factors, institutions factors and markets factors together determine the supply of lands, labors, capitals and technology elements' types, qualities, quantities and channels, conditions and related information farmers needed. It also constitutes the set of supply information and the getting opportunities for various elements farmers' production needed. Farmers who want to obtain the required agricultural production elements must firstly realize the supply information and grasp the acquiring opportunity of elements. Once farmers have no sensitive information searching ability, opportunity exploring ability, opportunity grasping ability, even if the supply of elements are more, they still can't obtain the needed agricultural production elements. Therefore, the opportunity grasping ability plays an important impact on the acquiring of and the availability of farmers' agricultural production elements.

\section{The Function of the Investment Ability}

In the condition of having the opportunity of elements' acquiring, the investment capacity of farmers become the primary decision conditions for the land, labor, capital and technology elements famers needed success getting and the advantages and disadvantages obtaining channels. Without enough investment capacity, agricultural production elements farmers needed is impossible or the getting status will be poorer. Therefore, the investment capacity of farm production plays an important role on the access and availability of agricultural production elements farmers needed.

\section{The Function of Social Capitals}

Except the grasping opportunity ability and the investment ability, the social capitals also plays an important role on the lands, labors, capitals and technologies elements' 
price and transaction costs, which would ultimately affect the access channels, access difficulty and access costs of farmers' agricultural production elements, and decide the availability of farmers' production elements.

\section{Conclusions}

The availability of agricultural production elements is the key of farmers' operation decision-making and income increasing. This study show that: i) Resources endowment have a direct impact on the supply of agricultural production elements. Geographic conditions not only together with resources endowment decide the supply of elements, but also directly reflect the resources endowment. ii) The formal and informal systems of property rights and transaction have important influence on the obtained of agricultural production elements through the supply and demand restrictions. iii) Elements markets scale, transparency and organized directly affect the availability of agricultural production elements farmers needed through the supply and the transaction efficiency of agricultural production elements. iv) The market opportunity grasping ability, the investment capacity of farm and social capitals will directly influence the access efficiency of agricultural production elements through the acquisition price and difficult of agricultural production elements.

On this basis, we can put forward some countermeasures to overcome these obstacles. We should promote the development of rural markets as the guidance of increasing agricultural production factors of liquidity, promote the farmers diverged as the guidance of improving the supply of land situation, improve the rural financial inclusion as the guidance of increasing the supply of agricultural capital elements level, improve the level of agricultural technical services as the guidance of increasing the supply ability of agricultural technology elements, promote farmers "exchange rights" in China as the guidance of improving the economy practical ability of farmers.

\section{Acknowledgement}

This research was financially supported by the National Natural Science Foundation (Grant No. 71603220), the Ministry of Education of Humanities and Social Science Project (Grant No. 16XJC790004), the Chongqing Social Sciences Planning Project (Grant No. 2015BS075), the Southwest University of Political Science \& Law Research Project (Grant No.2015XZQN-12) and the Southwest University of Political Science \& Law Teaching Reform Project (Grant No. 2015C11).

\section{References}

[1] Intizar Hussain etc, Irrigation, productivity and poverty linkages in irrigation systems in Java Indonesia, Water Resources Management. 20 (2006).

[2] Fan S., etc, Should developing countries invest more in less-favored areas? --- An empirical analysis of rural India, Economic and Political Weekly. 22 (2000).

[3] Ahmadk, Access denied to essential medicines in developing world, Lancet In feet Dis., 2 (2002).

[4] Schunemann. H., Kunz R., Falek-Ytte: Y., Procedures and methods of benefit assessments for medicines in Germany: Give the child a name, Eur Health Eeon, 2009. 
[5] World Health Organization, The selection and use of essential medicines. Report of the WHO Expert Committee, 1977.

[6] World Health Organization, The rational use of drugs, Report of the Conference of Experts, Nairobi, 1985. 